Trindade, I. A., Ferreira, C., \& Pinto-Gouveia, J. (2015). Inflammatory bowel disease: The harmful mechanism of experiential avoidance for patients' quality of life. Journal of Health Psychology, 1-11. doi: 10.1177/1359105315587142

The final publication is available at SAGE Journals via hpq.sagepub.com/content/early/2015/06/03/1359105315587142 


\section{Inflammatory bowel disease:}

The harmful mechanism of experiential avoidance for patients' quality of life

Inês A. Trindade, MSc, PhD student ${ }^{1}$ *

Cláudia Ferreira, $\mathrm{PhD}^{1}$

José Pinto-Gouveia, $\mathrm{MD}, \mathrm{PhD}^{1}$

${ }^{1}$ CINEICC - Cognitive and Behavioural Centre for Research and Intervention

Faculty of Psychology and Education Sciences

University of Coimbra, Portugal

* Correspondence concerning this article should be addressed to:

Inês A. Trindade

Email: ines.almeidatrindade@gmail.com 


\begin{abstract}
This study aimed to test the effects of inflammatory bowel disease symptomatology and associated medical complications on physical and psychological quality of life and to explore whether these relationships are mediated by experiential avoidance. A total of 200 inflammatory bowel disease patients reported demographic and medical data and completed self-report instruments. Results revealed that the tested model presented an excellent fit, explaining $51 \%$ of physical quality of life and $53 \%$ of psychological quality of life. Inflammatory bowel disease-associated complications directly impacted on physical quality of life, and experiential avoidance significantly mediated the relationships between inflammatory bowel disease symptomatology and physical and psychological quality of life. These results highlight the importance of implementing psychological interventions for inflammatory bowel disease patients.
\end{abstract}

Keywords: Acceptance and commitment therapy, Crohn's disease, experiential avoidance, inflammatory bowel disease, quality of life, ulcerative colitis. 


\section{Introduction}

Inflammatory bowel disease (IBD) is characterized by a chronic, incurable and relapsing inflammation of the intestinal system, caused by the deregulated activation of the immune system (Hanauer, 2006; Marks et al., 2006). The two most common types of IBD are Crohn's disease (CD) and ulcerative colitis (UC). While CD can involve any area of the gastrointestinal tract allowing patches of healthy bowel in between the affected areas, UC is limited to the large intestine and comprises a continuous area of inflammation (Ordás et al., 2012).

The onset of these conditions usually occurs between 15 and 30 years of age, with a second smaller peak between 50 and 70 years (Andres and Friedman, 1999). Although the aetiology is unknown, IBD seems to result from a combination between genetic and environmental factors (Crohn's \& Colitis Foundation of America (CCFA), 2005a) and is most prevalent in North America and Europe, in urban areas, and among individuals of Jewish descent (Fauci et al., 2008; Loftus and Sandborn, 2003; Soon et al., 2012).

IBD has an unpredictable course with periods of exacerbations (flare-ups) and remissions (when the disease is relatively inactive) and comprises a variety of symptoms such as abdominal pain, persisting diarrhoea, fever, rectal bleeding, loss of appetite, weight loss, nausea and fatigue. These manifestations cause temporary and permanent damages to the intestines, increasing the risk of colorectal cancer and other intestinal-related complications (e.g. fissures and abscesses) (Farraye et al., 2010). Furthermore, there may also be present extraintestinal complications such as anaemia, joint pain and swelling, arthritis, osteoporosis, skin lesions, mouth sores, hepatic problems, disturbances in lung function and ocular inflammation (Levine and Burakoff, 2011). 
Treatment aims at stabilizing the illness and usually involves taking oral medications. While corticosteroids are commonly prescribed to induce remission during flare-ups, the prevention of relapses and complications is often achieved with 5aminosalicylate-based compounds or immunosuppressive agents that are used on an indefinite basis (CCFA, 2005b). Patients may also undergo surgery to provide better symptom control. Nonetheless, when conventional therapy fails, treatment with the tumour necrosis factor alpha or antibiotics can be prescribed (CCFA, 2005b).

Although IBD has a low mortality rate and is not considered terminal (Irvine, 2004), the effects of these chronic pathologies on quality of life (QoL) are considered major. Indeed, it has been vastly reported that patients' psychosocial functioning and health-related QoL are significantly impaired during flare-ups and also during remission (e.g. Graff et al., 2006; Janke et al., 2005; Porcelli et al., 1996; Verma et al., 2001). During exacerbations of the illness, QoL is significantly compromised due to the debilitating IBD symptoms and the consequent inability to perform regular routines (such as jobs, attending school and leisure activities). Nonetheless, patients' QoL and psychological functioning during remission also tend to be poorer comparatively to the normal population (Blondel-Kucharski et al., 2001; Graff et al., 2009; Guthrie et al., 2002). This may be due to prolonged exposure of IBD-related pain and distress (Faust et al., 2012) and to the presence of persisting concerns regarding lack of energy, body image, the course of the disease, the potential need for surgery and the risk of developing cancer (Canavan et al., 2006; Casati et al., 2000). Furthermore, impaired QoL and psychological functioning on IBD are associated with more relapses and additional medical complications, intensifying the disease process in a cycle of inflammation and psychological suffering (e.g. Levenstein, 2004; Simrén et al., 2002). 
Psychological suffering has been the focus of a wide range of recent literature indicating that it is the result of more than direct negative experiences (such as pain, fatigue and unwanted thoughts or emotions), being mainly caused by the way one deals with those adverse experiences (Hayes et al., 2012; Pinto-Gouveia et al., 2014; Segal et al., 2002). In certain circumstances, IBD patients may experience bodily sensations, memories, thoughts or emotions as harmful or threatening, interpreting them as debilitating or as signs of a bad prognosis. As a result, they may learn to cope with these experiences by trying to control or avoid them. Acceptance and commitment therapy (ACT; Hayes et al., 2012) conceptualizes this phenomenon as experiential avoidance a process that comprises excessive negative evaluations of unwanted inner events, unwillingness to experience them and efforts to control or eliminate them (Bach et al., 2008; Hayes et al., 2012).

This experienced need to control private events (such as pain, fear or anxiety) is considered a central problem due to its long-term effects. Indeed, although focusing on control induces short-term positive consequences, these strategies are usually restrictive and hardly active and meaningful. Consequently, behaviour gradually becomes more inflexible and narrow and the individual tends to feel disconnected from his or her meaningful life pursuits. Avoidance of internal experiences has thus been repeatedly linked to the increased impact of those experiences on one's wellbeing (e.g. Hayes et al., 2004). Recent studies have indicated that the development of acceptance towards inner events, on the other hand, is associated with lower levels of psychopathology, physical and psychosocial disability and pain intensity on chronic pain patients (e.g. Costa and Pinto-Gouveia, 2011; McCracken and Eccleston, 2003; Pinto-Gouveia et al., 2015), with less anxiety and distress in cancer patients (e.g. Branstetter et al., 2004) and with physiological improvements on diabetes (Gregg et al., 2007). 
Given that experiential avoidance has been considered an important mechanism in physical and psychological functioning, this study aims to analyse whether the relationship between IBD symptomatology and physical and psychological QoL is mediated through that process. We expect that higher levels of IBD symptomatology will be associated with lower QoL (particularly psychological well-being) via the mechanism of experiential avoidance. To our present knowledge, this is the first study exploring the effect of experiential avoidance on QoL in an IBD sample.

\section{Methods}

\section{Procedures}

An invitation to participate in this study was electronically sent to the patients registered in the Portuguese Association for IBD (Associação Portuguesa para a Doença Inflamatória do Intestino (APDI)), according to the following inclusion criteria: (1) 18 years old or older and (2) diagnosis of IBD. Attached to the invitation were detailed information regarding the study (its aims, voluntary and character and confidential nature), and a link to the online platform with the informed consent and test battery. A total of 212 patients answered to this invitation. Three individuals declined to take part in the study, and 209 IBD patients signed the informed consent and completed the test battery on the online platform. Of these participants, nine patients were excluded from this study for being pregnant or reporting other severe illnesses (such as breast cancer, tuberculosis and fibromyalgia) or psychiatric disorders (bipolar disorder, generalized anxiety disorder and panic disorder).

\section{Measures}


Participants were asked about their demographic and medical data. The medical data concerned type of illness (CD, UC or IBD-unknown), IBD symptoms present in the last month (e.g. fatigue, abdominal pain, diarrhoea, bloody stools, nausea and fever), medical complications associated with IBD, time since diagnosis and number of hospitalizations and surgeries. Participants additionally completed self-report measures of QoL and experiential avoidance.

World Health Organization Brief Quality-of-Life Assessment Scale. The World Health Organization Brief Quality-of-Life Assessment Scale (WHOQOL-BREF) is a 26-item self-report measure of QoL with four domains (physical, psychological, social relationships and environment) and two additional items assessing general QoL (Canavarro et al., 2007; WHOQOL Group, 1998). Respondents select the number on a 5-point Likert scale that best represents their subjective perception of their QoL; higher scores indicate therefore a perception of higher QoL. This measure has presented adequate psychometric properties in the original ( $\alpha$ s between .66 and .84) and Portuguese validation studies ( $\alpha$ s between .67 and .87).

Acceptance and Action Questionnaire-II. The Acceptance and Action Questionnaire-II (AAQ-II) is a self-report instrument that assesses experiential avoidance (Bond et al., 2011; Pinto-Gouveia et al., 2012). It comprises seven items (e.g. 'I worry about not being able to control my worries and feelings') which the participant evaluates on a 7-point Likert scale (1: Never true, 7: Always true) according to their accuracy. Higher scores reveal higher levels of experiential avoidance. The AAQ-II presented good internal consistencies in both the original study (with a mean $\alpha$ of .84 across six samples) and the Portuguese validation $(\alpha=.90)$. The study variables' Cronbach's alphas are presented in Table 2. 


\section{Participants}

The final sample of this article included 200 Portuguese IBD patients (60 males and 140 females) of ages comprised between 18 and 76 years old $(M=35.85$; standard deviation $(S D)=10.71)$, and with completed years of education varying from 6 to $22(M$ $=14.29 ; S D=2.90)$. Concerning the participants' socioeconomic status, $8.5 \%$ presented a low status, $46 \%$ presented a medium status and $26 \%$ a high socio-economic status (Simões, 1994). Moreover, 12\% were college students, $4 \%$ were unemployed and $3.5 \%$ were retired. Furthermore, $90.50 \%$ resided in an urban region, while $9.50 \%$ resided in a rural location. Regarding the participants' marital status, 52\% were married, $41.50 \%$ single, $5.50 \%$ divorced and $1 \%$ widowed.

In what concerns medical information, $55 \%$ of the participants had $\mathrm{CD}, 42 \%$ had UC, while the rest (3\%) reported being under the diagnostic process (IBD-unknown). Time since diagnosis varied between 1 month and 40 years, with a mean of 8.47 years $(S D=6.67$ years). Furthermore, $41 \%$ of the sample reported presenting one or more medical complications associated with IBD $(M=1.41 ; S D=.77)$, such as osteoarticular complaints $(20.5 \%$ of the total sample), anorectal pathology $(8 \%)$ and respiratory complaints (7.5\%). The number of hospital admissions varied between 0 and $23(M=$ $2.10 ; S D=3.54)$, and the number of surgeries between 0 and $10(M=.51 ; S D=1.31)$. Detailed information concerning the participants' medical information is given in Table 1.

Analytic strategy

Data analyses were conducted using IBM SPSS Statistics 20 (IBM Corp, 2011) and path analyses were performed using the software AMOS. 
Preliminary data analyses were conducted to examine the adequacy of the data for analysis. Pearson correlation coefficients were performed to explore the relationships between study variables (Cohen et al., 2003). Two hierarchical multiple regressions were conducted to explore the effect of IBD symptoms and associated complications on physical and psychological QoL.

Path analyses (MacKinnon, 2008), a structural equation modeling (SEM), were performed to examine the relationships between study variables in the theoretical model. This statistical methodology enables the simultaneous analysis of structural relationships and the simultaneous exploration of direct and indirect paths (Schumacker and Lomax, 2004). The estimation of the model path coefficients and the computation of fit statistics were conducted through the maximum likelihood method. Furthermore, the following goodness-of-fit indices were used to examine the adequacy of the model: Chi-square $(\chi 2)$, comparative fit index (CFI), Tucker-Lewis index (TLI), incremental fit index (IFI), normed fit index (NFI) and the root mean square error of approximation (RMSEA) with 95\% confidence interval (CI). To test mediation effects, the bootstrap procedure (with 2000 resamples) was used to create $95 \%$ bias-corrected CIs around the standardized estimates of total, direct and indirect effects. The effect is considered statistically significant $(p<.05)$ if, on the interval between the lower and the upper bound of the $95 \%$ bias-corrected CI, is not included the value of 0 (Kline, 2005).

\section{Results}

\section{Preliminary analyses}

Univariate and multivariate normality was examined by the values of skewness and kurtosis. The skewness values ranged from -0.55 to 0.30 , while the values of 
kurtosis ranged from -0.51 to 0.15 . Results indicated that the distribution of the data were normal (Kline, 2005). Furthermore, variance inflation factor (VIF) values corroborated the suitability of the data (VIF $<5)$.

\section{Descriptive statistics and correlations}

The means and SDs of the study variables are reported in Table 2. Results from the correlation analyses (Table 2) revealed that all of the domains of QoL (physical, psychological, environmental, social and general) were negatively associated with IBD symptoms, with moderate to high correlation magnitudes. Furthermore, physical QoL was moderately linked to associated medical complications, which was also negatively related to environmental and general QoL. To note was also the inverse relationship found between general QoL and the number of hospital admissions. Time since diagnosis and the number of surgeries did not present associations with QoL. Finally, results also revealed that experiential avoidance (AAQ-II) presented moderate to high negative relationships with all of the QoL domains.

A partial correlation analysis controlling for socio-economic status was conducted and revealed that the direction and magnitude of the associations remained the same. Socio-economic status was therefore not included in the further analyses. However, partial correlation analyses controlling for age and gender revealed lower correlation magnitudes in the majority of the associations. Furthermore, the analysis controlling for age presented a significant relationship between time since diagnosis and psychological QoL. Age and gender were thus controlled for on the path analyses.

The effects of IBD symptomatology and associated complications on physical and psychological QoL 
In order to analyse whether IBD symptomatology and associated complications significantly impact on patients' physical and psychological QoL, two hierarchical multiple regressions were performed (Table 3).

Results concerning physical QoL revealed that when associated complications was entered as the independent variable and physical QoL as the dependent variable, a significant model was produced $(F(1.199)=23.01 ; p<.001 ; \beta=-.32 ; p<.001)$, accounting for $10 \%$ of the independent variable variance. On the second step, after the introduction of IBD symptoms, another significant model was produced $(F(1.199)=$ 82.56; $p$.001) which explained a total of $46 \%$ of physical QoL's variance. This model revealed that the variable IBD symptoms is the best predictor $(\beta=-.61 ; p<.001)$, with associated complications' effect being reduced to $-.18(p<.01)$.

Regarding psychological QoL, the same procedure was conducted. Results revealed that the first model, with associated complications as the independent variable and psychological QoL as the dependent variable, was significant $(F(1.199)=4.55 ; p$ $<.05 ; \beta=-.15)$ and accounted for $2 \%$ of psychological QoL's variance. In the second step, after the inclusion of IBD symptoms, the model explained $21 \%$ of the variance $(F(1.199)=25.82 ; p<.001)$, with IBD symptoms emerging as the only significant predictor $(\beta=-.44 ; p<.001)$.

\section{Path analyses - the mediational role of experiential avoidance}

The hypothesized model tested whether age, gender, IBD symptomatology (S) and associated complications (AC) impact on physical and psychological QoL, through the effect of increased experiential avoidance (AAQ-II). This model was first examined through a fully saturated model (i.e. 0 degrees of freedom), consisting of 37 parameters. 
The saturated model explained 54\% of physical QoL, 53\% of psychological QoL and $15 \%$ of AAQ-II. Nonetheless, several path coefficients were not statistically significant: the direct effects of associated complications $\rightarrow$ psychological QoL $\left(b_{A C}\right.$ $=.91 ; S E=1.84 ; Z=.50 ; p=.621) ;$ gender $\rightarrow$ psychological $\mathrm{QoL}\left(b_{\text {gender }}=.1 .53 ; S E=\right.$ $2.02 ; Z=.76 ; p=.449) ;$ gender $\rightarrow$ AAQ-II $\left(b_{\text {gender }}=1.17 ; S E=.1 .46 ; Z=.81 ; p\right.$ $=.421) ;$ age $\rightarrow$ psychological QoL $\left(b_{\text {age }}=-.13 ; S E=.08 ; Z=-1.57 ; p=.116\right) ; \mathrm{AC} \rightarrow$ AAQ-II $\left(b_{A C}=2.32 ; S E=1.32 ; Z=1.75 ; p=.08\right) ;$ age $\rightarrow$ AAQ-II $\left(b_{\text {age }}=-.09 ; S E\right.$ $=.06 ; Z=-1.59 ; p=.112) ;$ age $\rightarrow$ physical QoL $\left(b_{\text {age }}=-.15 ; S E=.08 ; Z=-1.88 ; p\right.$ $=.06)$ and the covariances between IBD symptomatology $\leftrightarrow$ age $\left(b_{S}=-5.03 ; S E=\right.$ $9.29 ; Z=-.54 ; p=.588)$; associated complications $\leftrightarrow$ gender $\left(b_{A C}=.02 ; S E=.02 ; Z\right.$ $=.90 ; p=.366)$. These paths were progressively removed and the respecified model was then tested.

The final adjusted model (Figure 1) accounted for 51\% of physical QoL and $53 \%$ of psychological QoL. Its evaluation revealed an excellent model fit, with a nonsignificant chisquare of $\chi^{2}(10)=14.95, p=.134$, and excellent goodness-of-fit indices $(\mathrm{CFI}=.99 ; \mathrm{TLI}=.97 ; \mathrm{IFI}=.99 ; \mathrm{NFI}=.96 ; \mathrm{RMSEA}=.05 ; p=.449 ; \mathrm{Kline}, 2005)$.

Furthermore, all individual path coefficients were statistically significant and in the expected directions. Associated complications directly predicted lower levels of physical QoL with an effect of $-.16\left(b_{A C}=-6.20 ; S E=1.77 ; Z=-3.50 ; p<.001\right)$. Furthermore, AAQ-II also presented direct negative effects on physical QoL $(\beta=-.27$; $\left.b_{A A Q-I I}=-.54 ; S E=.10 ; Z=-5.17 ; p<.001\right)$ and psychological QoL $\left(\beta=-.61 ; b_{A A Q-I I}=\right.$ $-.1 .15 ; S E=.10 ; Z=-11.80 ; p<.001)$.

Concerning the effects of IBD symptoms on physical QoL, results revealed that IBD symptoms presented a total effect of -.62 , with a direct effect of $-.52(b S=-.80$; 
$S E=.08 ; Z=-9.74 ; p<.001)$ and an indirect effect of $-.09(95 \% \mathrm{CI}=-.15$ to $-.05 ; p$ $=.001)$, partially operated through AAQ-II.

Moreover, results also showed that IBD symptoms presented a total effect of -.45 on psychological QoL, with a direct effect of $-.24\left(b_{S}=-.35 ; S E=.08 ; Z=-4.68\right.$; $p<.001)$ and an indirect effect of $-.21(95 \% \mathrm{CI}=-.29$ to $-.13 ; p=.001)$ through the mechanisms of AAQ-II.

In brief, the tested model explained $51 \%$ of physical QoL and $53 \%$ of psychological QoL and revealed experiential avoidance as a significant mediator of the effects of IBD symptomatology on physical and psychological QoL.

\section{Discussion}

IBD is a group of chronic, episodic inflammatory conditions of the large and small intestines, caused by the deregulated activation of the immune system. IBD compromises psychological and health-related QoL during exacerbations of the illness and also during remission (e.g. Graff et al., 2006). The debilitating symptoms of IBD, the consequent inability to perform daily routines and fears about the future (e.g. potential need for surgery or risk of developing colon cancer) are pointed as central in the determination of the patients' QoL (Canavan et al., 2006; Casati et al., 2000; Faust et al., 2012). At the same time, the literature regarding ACT (Hayes et al., 2012) has indicated that psychological suffering depends more on the way one deals with adversities than on the adversities themselves. Namely, several studies have shown the pervasive effect of experiential avoidance on mental health and QoL on different physical conditions. Nevertheless, the role of experiential avoidance on IBD patient's QoL has never been explored, being that therefore the aim of this study. 
The sample comprised in this article consisted of 200 individuals of both genders, diagnosed with a form of IBD, recruited on an online platform through the APDI. Time since diagnosis of the majority of the patients varied between 1 and 10 years. Furthermore, the most reported associated medical complications were osteoarticular manifestations (20.5\%), although there were also present other common complications of IBD (such as anorectal pathology, respiratory complaints or dermatological complaints) also reported by the literature (Farraye et al., 2010; Levine and Burakoff, 2011).

Results regarding the sample's QoL revealed that comparatively to the Portuguese healthy population, IBD patients presented lower QoL scores in all domains, especially in the general and physical dimensions (Canavarro et al., 2007). Additionally, results from the correlation analyses showed that all of the assessed QoL domains presented moderate to high associations with higher incidence of IBD symptoms (e.g. abdominal pain, persistent diarrhoea and rectal bleeding). Moreover, physical, psychological, environmental and general QoL were also negatively linked with associated medical complications. This seems to corroborate that QoL in IBD is associated with the diseases' symptomatology and associated complications. It was also demonstrated that all QoL domains presented moderate to high relationships with experiential avoidance (AAQ-II), further indicating that IBD patients' well-being is also inversely linked with the level of control and avoidance they present towards inner experiences.

Multiple regression analyses indicated that physical QoL is dependent upon the level of IBD symptomatology and the occurrence of associated complications. This model explained $45 \%$ of physical QoL and revealed IBD symptomatology as the best predictor. The same model was replicated with psychological QoL as the dependent 
variable, and it was revealed that IBD symptomatology was the only predictor, accounting for $21 \%$ of psychological QoL.

To better explore these findings, path analyses were performed aiming to analyse the mediational role of experiential avoidance on those associations, while controlling for age and gender. Results revealed that the tested model presented a very good fit to the empirical data and explained a total of $51 \%$ of physical QoL and $53 \%$ of psychological QoL. Associated medical complications directly predicted lower physical QoL, not being mediated by the emotion regulation process. Nevertheless, the impact of IBD symptomatology on physical and psychological QoL was partially mediated by experiential avoidance. This indicates that even though IBD symptoms directly impact on the patient's physical and psychosocial well-being, the attempt to control or avoid inner experiences significantly amplifies that association. The same pattern has been found on patients with other diseases, such as chronic pain (e.g. Costa and PintoGouveia, 2011), cancer (e.g. Branstetter et al., 2004) and diabetes (Gregg et al., 2007).

Consistent with the theoretical approach, the tested model's findings also suggest that the presence of IBD-related symptoms may trigger more unwanted private events (with the seeming need to control them) than the presence of associated medical complications. Patients experiencing IBD symptomatology may present high levels of pain/discomfort and unwanted thoughts or emotions concerning the symptoms, the illness itself or its prognosis (e.g. the symptoms never going away, starting a flare-up, becoming unable to perform daily routines and needing to take more medication). As these experiences may easily be perceived as threatening, patients may engage in avoidance and control strategies to undermine them which, as shown by the present model, hold a detrimental effect on physical and psychological well-being. 
It is nevertheless important to acknowledge the limitations of this study. First, the clinical sample was collected using an Internet-based survey, a cost-benefit method that may have limited the collection of a representative sample of Portuguese IBD patients. Other limitation of the present sample is the association found between age and gender, which (although weak) was not expected. This association seems to translate that, in this sample, older participants tend to be males. Furthermore, the tested model is restrained since other emotion regulation processes are probably involved in the analysed associations. This model was intentionally limited to specifically explore the impact of experiential avoidance on QoL. Finally, the main limitation of this study is its cross-sectional nature which does not allow causal interpretations; future studies should focus therefore on the longitudinal and experimental research of emotion regulation processes' role in IBD patients' QoL.

To sum up, this study offers new data concerning the determinants of QoL on IBD patients, by uncovering the damaging mediational effect of experiential avoidance on the association between IBD-related symptomatology and physical and psychosocial functioning. It therefore highlights the importance of implementing psychological interventions aiming at developing acceptance in IBD patients, which unfortunately is usually a contradictory reality, specifically in Portugal.

\section{Acknowledgements}

We would like to thank the Portuguese Association for IBD (Associação Portuguesa para a Doença Inflamatória do Intestino; APDI) for their valuable help during the recruitment process of this study's sample.

\section{Funding}


Research by the first author (Inês A Trindade) is supported by a PhD Grant (SFRH/BD/101906/2014) sponsored by FCT (Portuguese Foundation for Science and Technology).

\section{References}

Andres, P. G., \& Friedman, L. S. (1999). Epidemiology and natural course of inflammatory bowel disease. Gastroenterology Clinics of North America, 28, 255-281. doi: 10.1016/S0889-8553(05)70056-X

Bach, P., Moran, D., \& Hayes, S. C. (2008). ACT in practice: Case conceptualization in Acceptance \& Commitment Therapy. Oakland, CA: New Harbinger.

Blondel-Kucharski, F., Chircop, C., Marquis, P., Corot, A., Baron, F., Gendre J. P., Colombel, J. F., \& Groupe d'Etudes Thérapeutique des Affections Inflammatoires Digestives (2001). Health-related quality of life in Crohn's disease: a prospective longitudinal study in 231 patients. American Journal of Gastroenterology, 98, 2915-2920. doi: 10.1016/S0002-9270(01)03243-9

Bond, F. W., Hayes, S. C., Baer, R. A., Carpenter, K. M., Guenole, N., Orcutt, H. K., Waltz, T., \& Zettle, R. (2011). Preliminary psychometric properties of the Acceptance and Action Questionnaire-II: A revised measure of psychological inflexibility and experiential avoidance. Behavior Therapy, 42, 676-688. doi: 10.1016/j.beth.2011.03.007

Branstetter, A. D., Wislon, K. G., Hildebrandt, M. \& Mutch, D. (2004). Improving psychological adjustment among cancer patients: ACT and CBT. Paper presented at the meeting of the Association for Advancement of Behavior Therapy, New Orleans'. 
Canavan, C., Abrams, K. R., Hawthorne, B., Drossman, D., \& Mayberry, J. F. (2006). Long-term prognosis in Crohn's disease: factors that affect quality of life. Alimentary Pharmacology \& Therapeutics, 23(3), 377-385. doi: 10.1111/j.13652036.2006.02753.x

Canavarro, M. C., Simões, M. R., Vaz Serra, A., Pereira, M., Rijo, D., Quartilho, M., Gameiro, S., Paredes, T., \& Carona, C. (2007). WHOQOL-Bref Instrumento de Avaliação da Qualidade de Vida da Organização Mundial de Saúde [WHOQOLBref Quality of Life Assessment Instrument from the World Health Organization]. In M. R. Simões, M. M. Gonçalves \& Almeida, L. S. (Coord.) Avaliação Psicológica: 46 Instrumentos válidos para a população portuguesa (Vol.III, pp. 77-100). Coimbra: Quarteto.

Casati, J., Toner, B. B., de Rooy, E. C., Drossman, D. A., \& Maunder, R. G. (2000). Concerns of patients with inflammatory bowel disease: A review of emerging themes. Digestive Diseases and Sciences, 45, 26-31.

Cohen, J., Cohen, P. West, S. \& Aiken, L. (2003). Applied multiple regression/correlation analysis for the behavioural sciences (3th ed.). New Jersey: Lawrence Erlbaum Associates.

Costa, J., \& Pinto-Gouveia, J. (2011). The mediation effect of experiential avoidance between coping and psychopathology in chronic pain. Clinical Psychology and Psychotherapy, 18, 34-47 doi: 10.1002/cpp.699

Crohn's and Colities Foundation of America (2005b). Living with IBD. [Brochure]. NY: Author.

Crohn's and Colitis Foundation of America (2005a). Living with Crohn's disease. [Brochure]. NY: Author. 
Farraye, F. A., Odze, R. D., Eaden, J., \& Itzkowitz, S. H. (2010). AGA technical review on the diagnosis and management of colorectal neoplasia in inflammatory bowel disease. Gastroenterology, 138(2), 746-774. doi: 10.1053/j.gastro.2009.12.035

Fauci, A. S., Braunwald, E., Kasper, D. L., Hauser, S. L., Longo, D. L., Jameson, J. L., \& Loscalz, J. (2008). Harrison's Internal Medicine, 17th ed. New York: McGraw-Hill Medical.

Faust, A. H., Halpern, L. F., Danoff-Burg, S., \& Cross, R. K. (2012). Psychosocial factors contributing to inflammatory bowel disease activity and health-related quality of life. Journal of Gastroenterology and Hepatology, 14, 173-181

Gibson, P. R., Weston, A. R., Shann, A., Florin, T. H., Lawrance, I. C., Macrae, F. A., \& Radford-Smith, G. (2007). Relationship between disease severity, quality of life and health-care resources in a cross-section of Australian patients with Crohn's disease. Journal of Gastroenterology and Hepatology, 22, 1306-1312. doi: $10.1111 / j .1440-1746.2007 .04930 . x$

Graff, L. A., Walker, J. R., \& Bernstein, C. N. (2009). Depression and anxiety in inflammatory bowel disease: a review of comorbidity and management. Inflammatory Bowel Diseases, 14, 1105-1118. doi: 10.1002/ibd.20873.

Graff, L. A., Walker, J. R., Lix, L. M., Clara, I., Rawsthorne, P., Rogala, L., Miller, N., Jakul, L., McPhail, C., Ediger, J., \& Bernstein, C. N. (2006). The relationship of inflammatory bowel disease type and activity to psychological functioning and quality of life. Clinical Gastroenterology and Hepatology, 4, 1491-1501. doi: 10.1016/j.cgh.2006.09.027

Gregg, J. A., Callaghan, G. M., Hayes, S. C., \& Glenn-Lawson, J. L. (2007). Improving diabetes self-management through acceptance, mindfulness, and values: A 
randomized controlled trial. Journal of Consulting and Clinical Psychology, 75, 336-343. doi: 10.1037/0022-006X.75.2.336

Guthrie, E., Jackson, J., Shaffer, J., Thompson, D., Tomenson, B., \& Creed, F. (2002). Psychological disorder and severity of inflammatory bowel disease predict health-related quality of life in ulcerative colitis and Crohn's disease. American Journal of Gastroenterology, 97, 1994-1999. doi: 10.1111/j.1572$0241.2002 .05842 . x$

Hanauer, S. B. (2006). Inflammatory bowel disease: epidemiology, pathogenesis, and therapeutic opportunities. Inflammatory Bowel Diseases, 12(1), 3-9. doi: 10.1097/01.MIB.0000195385.19268.68

Hayes, S. C., Strosahl, K., Bunting, K., Twohig, M., \& Wilson, K. G. (2004) What is Acceptance and Commitment Therapy? In Hayes S. C., Strosahl K. D. (Eds) A practical guide to Acceptance and Commitment Therapy. New York: Springer Science, pp 3-29.

Hayes, S. C., Strosahl, K. D., \& Wilson, K. G. (2012) Acceptance and commitment therapy: The process and practice of mindful change (2nd ed.). The Guilford Press: New York.

Irvine, E. J. (2004). Review article: patients' fears and unmet needs in inflammatory bowel disease. Alimentary Pharmacology \& Therapeutics, 20(4), 54-59. doi: 10.1111/j.1365-2036.2004.02053.x

Janke, K. H., Klump, B., Gregor, M., Meisner, C., \& Haeuser, W. (2005). Determinants of life satisfaction in inflammatory bowel disease. Inflammatory Bowel Diseases, 11, 272-286. doi: 10.1097/01.MIB.0000160809.38611.f7

Kline, R. B. (2005). Principle and practice of structural equation modeling. New York: Guilford. 
Levenstein, S. (2004). Embracing complexity: what determines quality of life in inflammatory bowel disease? European Journal of Gastroenterology \& Hepatology, 14, 1253-1255. doi: 10.1097/00042737-200412000-00002.

Levine, J. S., \& Burakoff, R. (2011). Extraintestinal manifestations of inflammatory bowel disease. Journal of Gastroenterology and Hepatology, 7, 235-241.

Loftus Jr, E. V., \& Sandborn, W. J. (2003). Epidemiology of inflammatory bowel disease. Gastroenterology Clinics of North America, 31, 1-20. doi: $10.1016 / 50889-8553(01) 00002-4$

MacKinnon, D. P. (2008). Introduction to Statistical Mediation Analysis. Mahwah, NJ: Erlbaum.

Marks, D. J., Harbord, M. W., MacAllister, R., Rahman, F. Z., Young, J., Al-Lazikani, B., Lees, W., Novelli, M., Bloom, S., \& Segal, A. W. (2006). Defective acute inflammation in Crohn's disease: a clinical investigation. Lancet, 367(9511), 668-678. doi: 10.1016/S0140-6736(06)68265-2

McCracken, L. M., \& Eccleston C. (2003). Coping or acceptance: what to do about chronic pain? Pain, 105(1 - 2), 197 - 204. doi: 10.1016/S03043959(03)00202-1

Ordas, I., Eckmann, L., Talamini, M., Baumgart, D. C., \& Sandborn, W. J. (2012). Ulcerative colitis. Lancet 380, 1606-1619. doi: 10.1016/S0140-6736(12)601500

Pinto-Gouveia, J., Costa, J., \& Marôco, J. (2013). The first 2-years of Rheumatoid Arthritis: The influence of Acceptance on Pain, Physical Limitation and Depression. Journal of Health Psychology, 9. doi: 10.1177/1359105313499807

Pinto-Gouveia, J., Duarte, C., Matos, M., \& Fráguas, S. (2014). The Protective Role of Self-compassion in Relation to Psychopathology Symptoms and Quality of Life 
in Chronic and in Cancer Patients. Clinical Psychology \& Psychotherapy, 21, 311-323. doi: 10.1002/cpp.1838

Pinto-Gouveia, J., Gregório, S., Dinis, A., \& Xavier, A. (2012). Experiential avoidance in clinical and nonclinical samples. International Journal of Psychology and Psychological Therapy, 12(2), 139-156.

Podolsky, D. K. (2002). Inflammatory bowel disease. The New England Journal of Medicine, 347, 417-429. doi: 10.1056/NEJMra020831

Porcelli, P., Leoci, C., \& Guerra, V. (1996). A prospective study of the relationship between disease activity and psychologic distress in patients with inflammatory bowel disease. Scandinavian Journal of Gastroenterology, 31, 792-796.

Schumacker, R. E. \& Lomax, R. G. (2004). A beginner's guide to structural equation modeling (2nd edition). Mahwah, NJ: Lawrence Erlbaum Associates.

Segal, Z. V., Williams, J. M. G., \& Teasdale, J. D. (2002). Mindfulness-based cognitive therapy for depression: A new approach to preventing relapse. New York, NY: Guilford Press.

Simões, M.M.R (1994). Investigação no âmbito da aferição nacional dos Testes das Matrizes Coloridas de Raven [Investigation regarding the national aferition of the Raven's progressive matrices]. Doctoral dissertation presented to the Faculty of Psychology and Education Sciences of the University of Coimbra, Portugal.

Simrén, M., Axelsson, J., Gillberg, R., Abrahamsson, H., Svedlund, J., \& Björnsson, E. S. (2002). Quality of life in inflammatory bowel disease in remission: the impact of IBS-like symptoms and associated psychological factors. American Journal of Gastroenterology, 14, 389-396. doi: 10.1111/j.1572-0241.2002.05475.x

Soon, I. S., Molodecky, N. A., Rabi, D. N., Ghali, W. A., Barkema, H. W., \& Kaplan, G. G. (2012). The relationship between urban environment and the inflammatory 
bowel diseases: a systematic review and meta-analysis. BMC Gastroenterology, 12(1), 51. doi: 10.1186/1471-230X-12-51

Verma, S., Tsai, H. H., \& Giaffer, M. H. (2001). Does better disease-related education improve quality of life? A survey of IBD patients. Digestive Diseases and Sciences, 46, 865-869.

WHOQOL Group (1998). Development of World Health Organization WHOQOL-Bref Quality of Life Assessment. Psychological Medicine, 28, 551-558. 
Table 1

Sample's medical characteristics $(N=200)$

\begin{tabular}{|c|c|c|c|}
\hline & & $n$ & $\%$ \\
\hline \multirow{3}{*}{ Type of IBD } & Crohn's Disease & 110 & 55 \\
\hline & Ulcerative Colitis & 84 & 42 \\
\hline & IBD-unknown & 6 & 3 \\
\hline \multirow{5}{*}{$\begin{array}{l}\text { Time since } \\
\text { diagnosis }\end{array}$} & Until 6 months & 8 & 4 \\
\hline & 6 months to a year & 15 & 7.5 \\
\hline & $1-5$ years & 70 & 35 \\
\hline & $6-10$ years & 57 & 28.5 \\
\hline & $>10$ years & 50 & 25 \\
\hline \multirow{13}{*}{$\begin{array}{l}\text { Associated medical } \\
\text { complications }\end{array}$} & osteoarticular complaints & 41 & 20.5 \\
\hline & anorectal pathology & 16 & 8 \\
\hline & respiratory complaints & 15 & 7.5 \\
\hline & dermatological complaints & 10 & 5 \\
\hline & anaemia & 6 & 3 \\
\hline & optical problems & 3 & 1.5 \\
\hline & hepatic problems & 3 & 1.5 \\
\hline & duodenal ulcers & 2 & 1 \\
\hline & gingival complaints & 2 & 1 \\
\hline & autoimmune thyroiditis & 1 & 0.5 \\
\hline & intestinal occlusion & 1 & 0.5 \\
\hline & diverticula & 1 & 0.5 \\
\hline & high-grade dysplasia of the colon & 1 & 0.5 \\
\hline \multirow{3}{*}{ Number of hospital } & 0 & 77 & 38.5 \\
\hline & $1-5$ & 105 & 52.5 \\
\hline & $>5$ & 18 & 9 \\
\hline \multirow{3}{*}{ Number of surgeries } & 0 & 151 & 75.5 \\
\hline & 1 & 29 & 14.5 \\
\hline & $>1$ & 20 & 10 \\
\hline
\end{tabular}




\section{Table 2}

Means (M), Standard Deviations (SD), Cronbach's alphas and Intercorrelation scores on self-report measures and self-reported medical data $(N=$ 200)

\begin{tabular}{|c|c|c|c|c|c|c|c|c|c|}
\hline & $\alpha$ & $M$ & $S D$ & $\begin{array}{l}\text { Time since } \\
\text { diagnosis }\end{array}$ & IBD symptoms & $\begin{array}{l}\text { Associated } \\
\text { medical } \\
\text { complications }\end{array}$ & $\begin{array}{l}\text { N. of hospital } \\
\text { admissions }\end{array}$ & N. of surgeries & AAQ-II \\
\hline Physical QoL & .87 & 62.48 & 18.93 & .06 & $-.65 * * *$ & $-.32 * * *$ & -.11 & .09 & $-.43 * * *$ \\
\hline Psychological QoL & .84 & 62.52 & 17.94 & .13 & $-.45 * * *$ & $-.15^{*}$ & .01 & .08 & $-.62 * * *$ \\
\hline Social QoL & .73 & 62.33 & 21.49 & .04 & $-.34 * * *$ & -.20 & .02 & .05 & $-.45^{* * *}$ \\
\hline Environmental QoL & .81 & 62.72 & 14.99 & .04 & $-.45 * * *$ & $-.25 * * *$ & -.06 & .06 & $-.39 * * *$ \\
\hline General QoL & - & 53.88 & 19.51 & .10 & $-.53 * * *$ & $-.27 * * *$ & $-.22 * *$ & -.03 & $-.47 * * *$ \\
\hline AAQ-II & .91 & 49.00 & 25.60 & -.11 & $.32 * * *$ & $.15^{*}$ & .06 & -.01 & - \\
\hline
\end{tabular}

Note. ${ }^{*} p<.05 ; * * p<.01 ; * * * p<.001$. Physical QoL, Psychological QoL, Social QoL, Environmental QoL, General QoL = subscales of the WHOQOL-BREF; AAQ-II = Acceptance and Action Questionnaire. 


\section{Table 3}

Hierarchical multiple regressions to analyse the impact of associated medical complications and IBD symptomatology on physical QoL and psychological QoL $(N=200)$

\section{Physical QoL Psychological QoL}

\begin{tabular}{lcccccccc}
\hline Predictor & $R^{2}$ & $\Delta R^{2}$ & $F$ & $\beta$ & $R^{2}$ & $\Delta R^{2}$ & $F$ & $\beta$ \\
Step 1 & .10 & .10 & $23.01^{* * *}$ & & .02 & .02 & $4.55^{*}$ & \\
As. complications & & & & $-.32 * * *$ & & & & $-.15^{*}$ \\
Step 2 & .46 & .45 & $82.56^{* * *}$ & & .21 & .20 & $25.82^{* * *}$ & \\
As. complications & & & & $-.18^{* * *}$ & & & & -.05 n.s. \\
IBD symptoms & & & & $-.61^{* * *}$ & & & & $-.44 * * *$ \\
\hline
\end{tabular}

$* p<.05 ; * * p<.01 ; * * * p<.001$.

As. complications $=$ associated medical complications; physical QoL and psychological $\mathrm{QoL}=$ subscales of the WHOQOL-BREF. 